ESJ Social Sciences

\title{
Mother Nature's Revolution and the COVID-19 Pandemic: A Scooping Review of COVID-19 and the Environment
}

\author{
Endurance Uzobo \\ Department of Sociology. Niger Delta University, Nigeria \\ Stanley E. Boroh \\ Department of Sociology and Anthropology, \\ Federal University Otuoke, Nigeria
}

Doi:10.19044/esj.2021.v17n19p100

Submitted: 19 January 2021

Accepted: 11 May 2021

Published: 30 June 2021
Copyright 2021 Author(s)

Under Creative Commons BY-NC-ND

4.0 OPEN ACCESS

Cite As:

Uzobo E. \& Boroh S.E. (2021). Mother Nature's Revolution and the COVID-19 Pandemic: A Scooping Review of COVID-19 and the Environment.

European Scientific Journal, ESJ, 17(19), 100. https://doi.org/10.19044/esj.2021.v17n19p100

\section{Abstract}

Many studies have solely focused on the negative impact of the coronavirus while ignoring the fact that the coronavirus was also a blessing in disguise to certain institutions. This study focuses on an exploration of some of the environmental-related benefits accruing from the outbreak of the coronavirus, which eventually led many countries of the world to declare a national lockdown. The study utilised secondary sources from 21 articles gleaned from hand-searched literature from various web pages and online news, accessed through google web page (google.com) between March to September 2020. Key search words used in the search were COVID-19 and the environment, benefits of COVID-19 to the environment, the environmental impact of COVID-19, and the environmental behaviour during COVID-19. The study reported that some positive benefits of COVID-19 concerning the environment from China, the United States of America, Europe, and Africa. Findings from the review indicated that almost all the continents in the world have experienced improve environmental quality as a result of the outbreak of the coronavirus. The study further added that one of the most important dividends arising from the outbreak is the positive change in behaviour in people towards the environment. It was, therefore, recommended that there is a need for nations of the world to leverage the 
window of opportunity provided by the coronavirus to encourage green economic behaviour to save the environment.

Keywords: Coronavirus, Environmental behaviour, Lockdown, Air quality, Greenhouse gases

\section{Introduction}

"And six days thou shalt sow thy land, and shalt gather in the fruits thereof: But the seventh year thou shalt let it rest and lie; that the poor of thy people may eat: and what they leave the beasts of the field shall eat. In like manner thou shalt deal with thy vineyard, and with thy olive yard" (Exodus 23:10-11).

God had earlier given the Jews the above instruction which is known as the Sabbatical year or Shmita by the Jews to allow regeneration of the earth. However, the Israelites disobeyed this instruction and one of the punishments which followed was that they were carried into captivity. In like manner, some environmentalist attributes the current outbreak of the coronavirus to be Mother Nature's revolution against unending and unabated plundering of earth's resources without alternative plans for regeneration. While this might just be an expression to support measures beyond human control to reclaim earth's resources, there is no doubt that during the period of the coronavirus outbreak, the earth has to some extend breathe a sigh of relief.

Historically, up to 2020, increases in the number of greenhouse gases produced since the beginning of the industrialisation era caused average global temperature on the Earth to rise, causing effects including the melting of glaciers and rising sea levels (Madhav, et al., 2017). In various forms, human activity caused environmental degradation and anthropogenic impact. Also, before the COVID-19 pandemic, researchers argued that reduced economic activity would help decrease global warming as well as air and marine pollution, allowing the environment to slowly flourish (Kopnina, et al., 2018; Rull, 2016).

Globally, one of the major threats to humanity has remained environmental-related social problems such as; global warming, climate change, desert encroachment, etc. These problems have spanned numerous environmental movements including Friends of the Earth, Green Peace, etc whose efforts at fighting for nature have achieved minimal or no success. Nonetheless, with the outbreak of the coronavirus between November and December 2019 in Wuhan China, the narratives have changed to some extent as the environment has accomplished some form of Succour.

Contrastingly, while most scholars have focused on the negative socioeconomic and health impact of the coronavirus, there is also a need to explore 
the positive environmental benefits of the pandemic. Thus, this paper aims to explore some positive environmental-related benefits emanating from the outbreak of the coronavirus disease especially during the period of the lockdown.

\section{Material and Methods}

This study is a scoping review. Given the nature of this study as a scoping review, published articles used in this study were gleaned from secondary sources and grey literature hand-searched from google. In the literature search, this study narrowed its focus on the articles published on the subject matter between March to September 2020. Key search words used in the search were COVID-19 and the environment, benefits of COVID-19 to the environment, the environmental impact of COVID-19, and the environmental behaviour during COVID-19, etc. The search for each of the key phrases was tailored towards continental-based scenarios. The search was generally conducted through the Google website (www.google.com). After this process, articles that did not properly address the main objectives of the study were excluded from the study. The search was generally conducted by the two authors (EU and SEB). After the two authors reached a mutual decision on selected articles, successful articles were reviewed for the study. Thus, the authors considered only articles that contained information addressing the positive impact of COVID-19 on the environment. Although, a few articles addressing how behavioural changes during pandemic situations were also reviewed. At the end of the screening of articles from the search, 21 articles were found to be very relevant to the study. They were therefore used in this scoping review.

\section{China}

As industries, transport networks, and businesses closed down in China, findings have indicated that there was a sudden drop in carbon emissions. In China, emissions fell $25 \%$ at the start of the year as people were instructed to stay at home, factories shuttered and coal use fell by $40 \%$ at China's six largest power plants since the last quarter of 2019. The proportion of days with "good quality air" was up $11.4 \%$ compared with the same time last year in 337 cities across China, according to its Ministry of Ecology and Environment (Henriques, 2020). Images from the NASA Earth Observatory show a stark drop in pollution in Wuhan, China, when comparing $\mathrm{NO}_{2}$ levels in early 2019 (top) and early 2020 (bottom). 


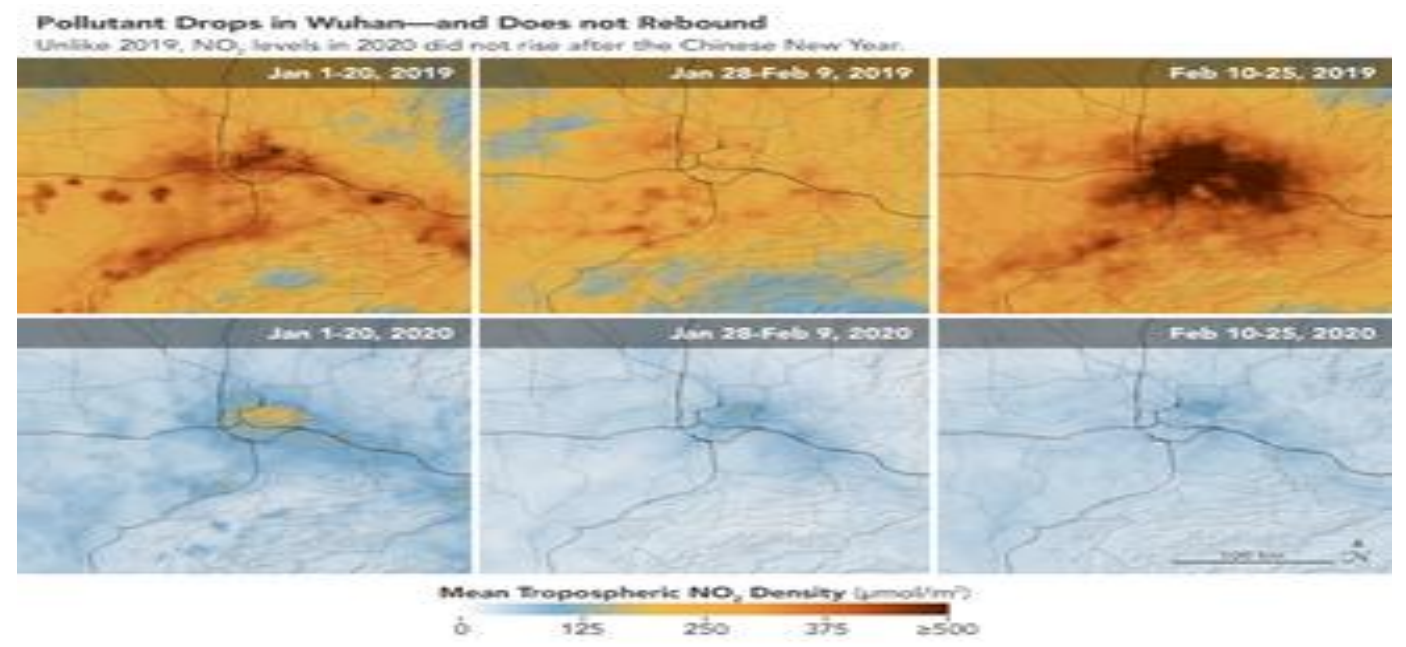

Fig. 1: Comparing Air Quality in Wuhan between 2019 and 2020

Source: Earth Observatory (2020)

The Centre for Research on Energy and Clean Air reported that methods to contain the spread of coronaviruses, such as quarantines and travel bans, resulted in a 25\% reduction in carbon emission in China (Myllyvirta, 2020; Venter, Aunan, Chowdhury, \& Lelieveld,2020) and 50\% reduction in nitrogen oxides emissions, (Zhang, et.al., 2020) which Earth systems scientists estimated may have saved at least 77,000 lives over two months (Burke, 2020; McMahon, 2020).

In the first month of the lockdowns, China produced approximately 200 million fewer metric tons of carbon dioxide than the same period in 2019, due to the reduction in air traffic, oil refining, and coal consumption. In the Hubei province of China, due to the coronavirus-related restrictions on industrial plants, facilities, and carbon-emitting machinery, there was a drastic reduction in the level of concentration of nitrogen dioxide $\left(\mathrm{NO}_{2}\right)$ and particulate matter (Zambrano-Monserrate, Ruano, \& Sanchez-Alcalde, 2020). This to a large extent improved the air quality and reduced air pollution.

\section{United States}

In the United States, it was recorded that greenhouse gas emissions and pollution dropped compared to previous years. For instance, pollution in New York was said to have dropped by nearly 50\%. Los Angeles was also said to have witnessed the best air quality in the past four decades (Shutterstock, 2020) [See Fig 3]. In Florida, researchers found out that both leatherback sea turtles and loggerhead turtles are thriving after a long time due to reduced human presence and waste in the water bodies (see Fig. 2). 


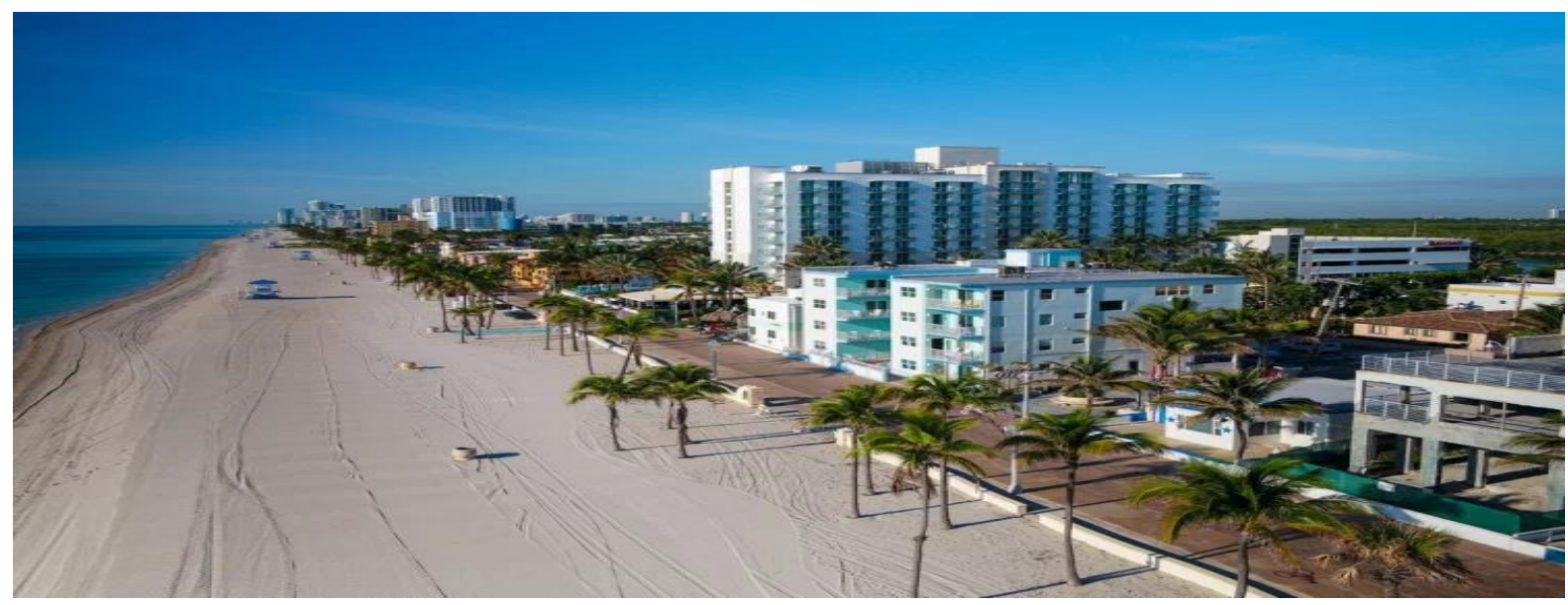

Fig. 2: A drone view of an empty Hollywood Beach, Florida, amid the COVID-19 lockdown.

Source: Shutterstock (2020).

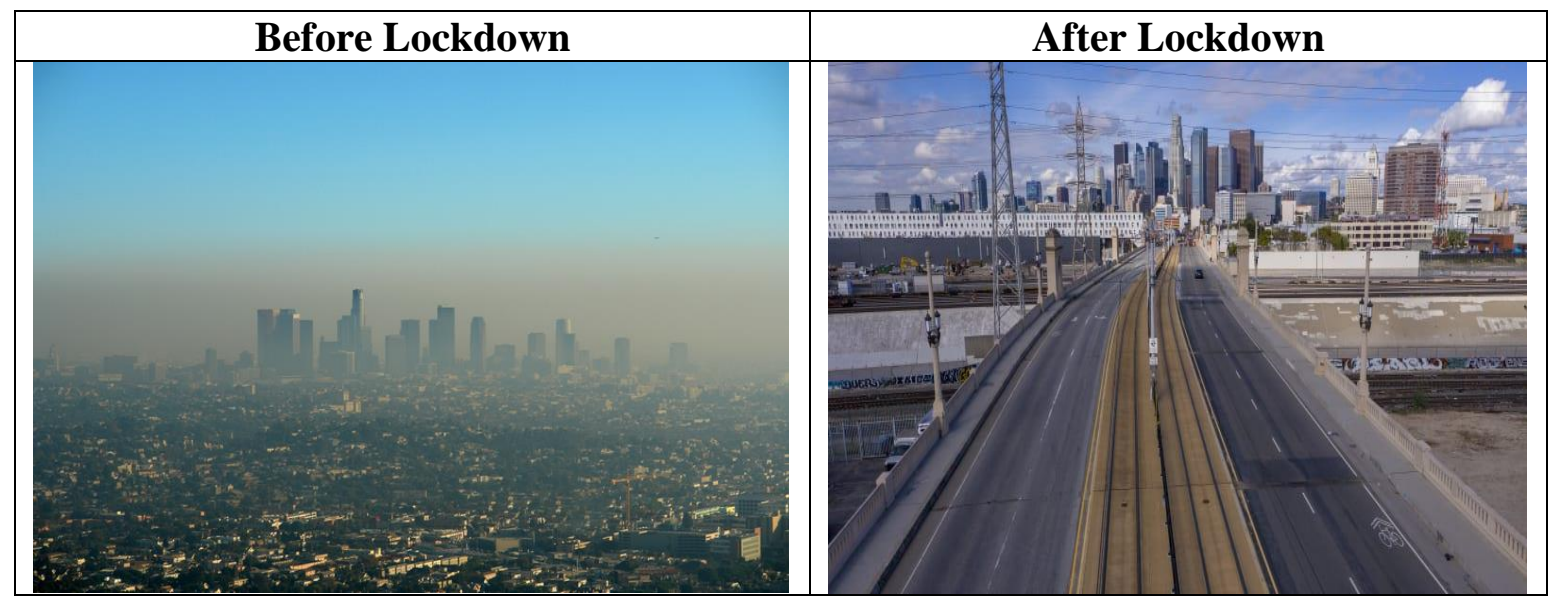

Fig. 3. A layer of Los Angeles before and After Lockdown

Source: David McNew (cited in Ghansiyal, 2020).

\section{Europe}

In Europe, satellite images showed that nitrogen dioxide (NO2) emissions were fading away in some parts of Italy, Spain and the UK. Giving reasons for the decline, Kimberly Nicholas, a sustainability science researcher at Lund University in Sweden, stated that this might have been a result of transport decline as transportation makes up to $23 \%$ of global carbon emissions (Henriques, 2020). It has previously been stated that driving and aviation are key contributors to emissions from transport, contributing about $72 \%$ and $11 \%$ of the transport sector's greenhouse gas emissions respectively (Henriques, 2020). 
Green (2020) also found out that between 1 January and 11 March 2020, which coincided with the lockdown in some European countries, the European Space Agency observed a marked decline in nitrous oxide emissions from cars, power plants, and factories in the Po Valley region in northern Italy. In Italy, a combo picture shows the skyline of Murcia, Spain, days before the national lockdown, amid the COVID-19 pandemic (See Fig. 4).

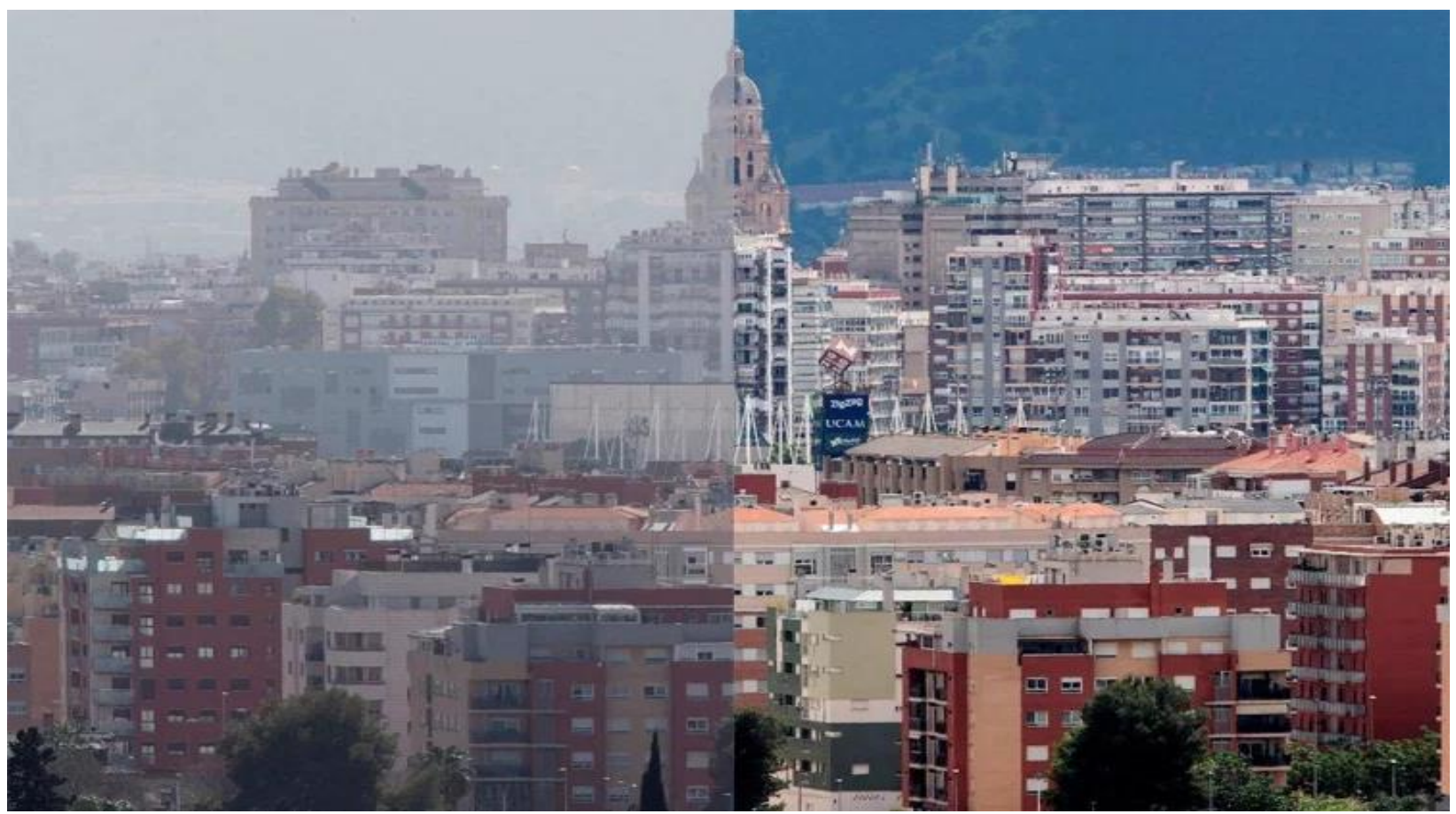

Fig 4. Skyline of Murcia, Spain before and after lockdown, February 2019 (left), April 2020 (right).

Source: Maarcial Guillen (cited in Shutterstock, 2020).

In Venice, Italy, as the number of tourists vanished from the waters due to the outbreak of the coronavirus, the canals cleared and experienced greater water flow and visibility of fish to the amazement of the residents (Saadat, Rawtani, \& Hussain, 2020) [See Fig 5]. Also, for the first time in a very long time, a beautiful jellyfish was spotted serenely swimming through near-transparent waters in the canals of Venice. This would have been an unthinkable sight just years ago (CNN, 2020). Additionally, Swans and dolphins were seen in the canals swimming playfully (Srikanth, 2020 


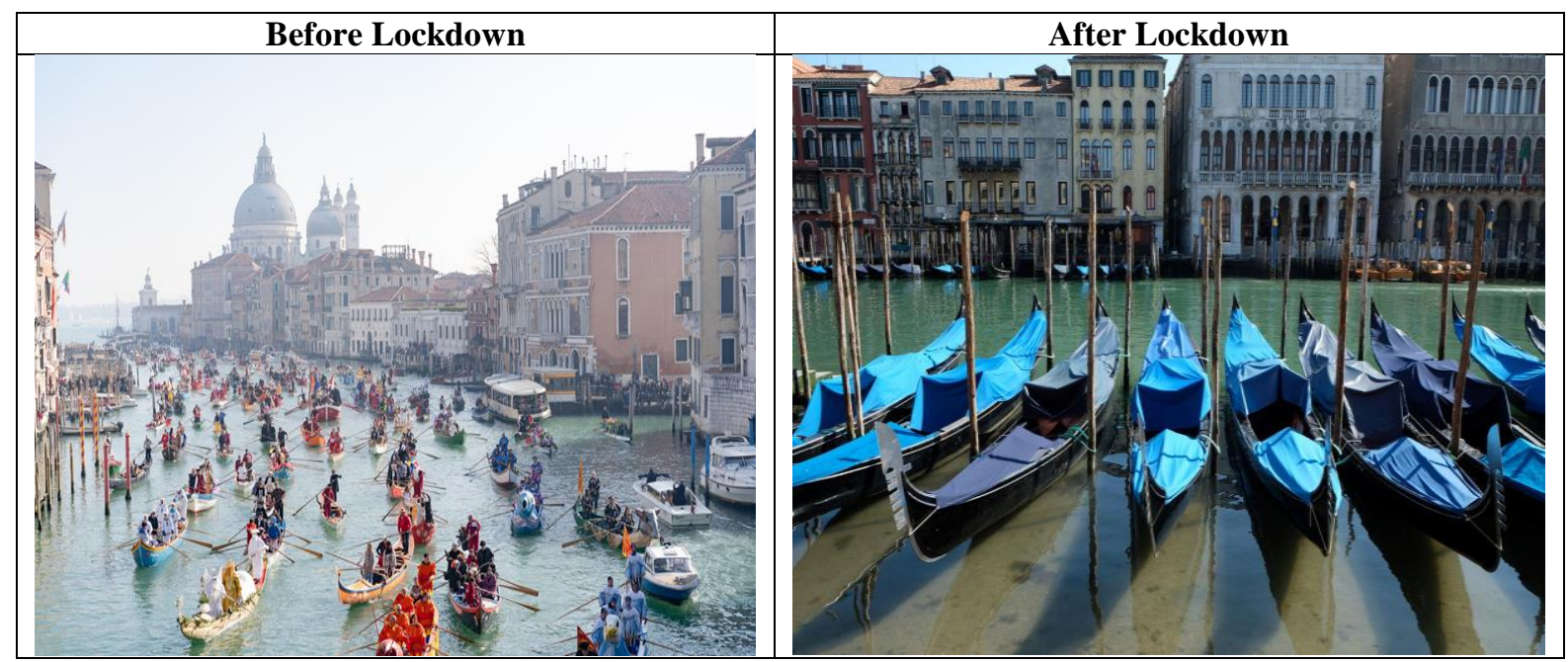

Fig 5. The waters of Venice before and after Lockdown

Source: Manuel Silvestri (cited in Ghansiyal, 2020).

\section{Africa}

Africa is not left out in counting the environmental benefit that accrued to the continent due to the outbreak of the coronavirus. For instance, in April, the breathtaking Mount Kenya became visible from Nairobi, an occurrence so rare that many believed photos of the event had been Photoshopped (See Fig. 6 ). After one photo went viral, older residents weighed in, remembering that, once upon a time, the air had been clear enough to see it regularly (Shutterstock, 2020).

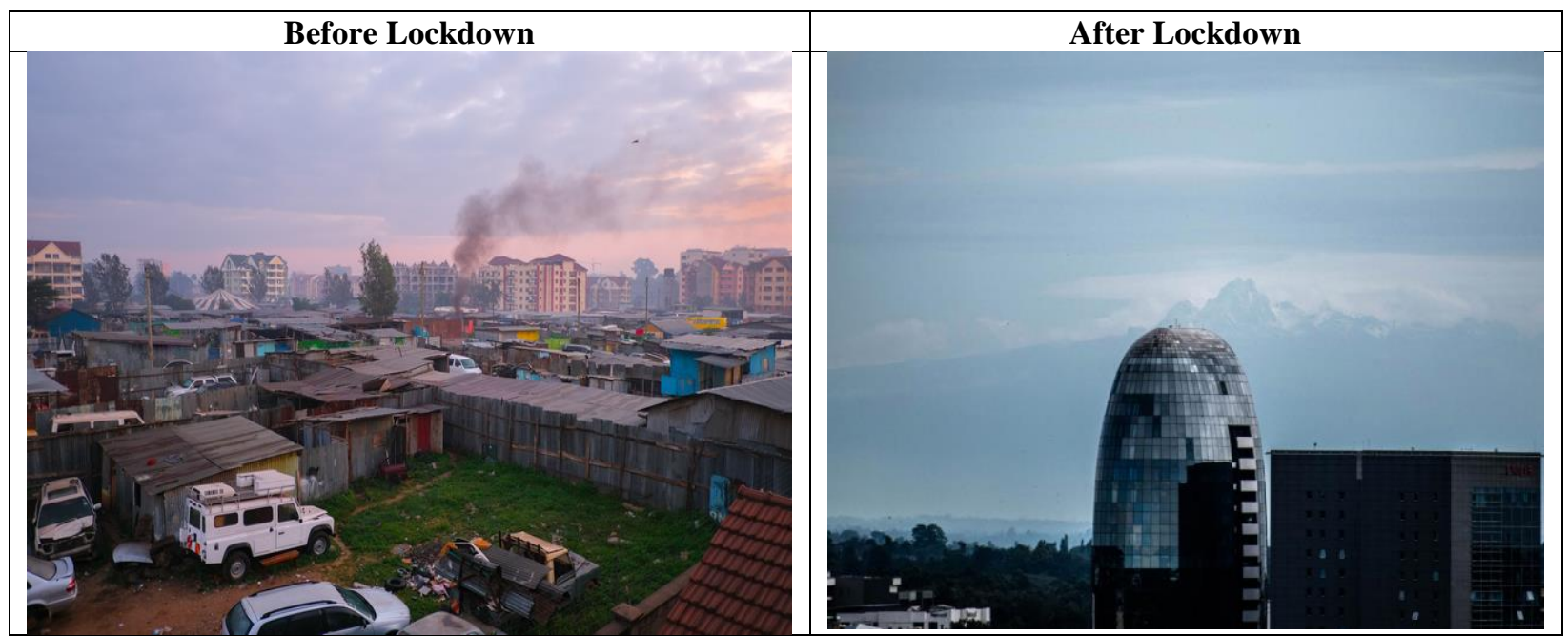

Fig. 6: The City of Nairobi before and after Lockdown

Source: Osman Siddiqui (cited in Ghansiyal, 2020). 
Manfred Braune, University of Cape Town (UCT) Director of Environmental Sustainability stated that while lockdown has been difficult for many sectors, including higher education, it yielded a range of interesting, unintended positive effects on the environment in Africa. Some of the positive benefits he outlined included a significant reduction in electricity and water consumption (by more than 50\%), near-zero vehicle and air travel emissions, and an almost complete reduction in waste generated (UTC, 2020).

\section{Behavioural Change to the Environment}

One of the most important benefits of the coronavirus outbreak to the environment is an increasing behavioural change towards the environment. While the current window of opportunity received by the physical environment will not last long as people go back to their normal lives, the behavioural changes might last a little longer if not permanent to most households. This is because as Kimberly Nicholas has opined (cited in Henriques, 2020), 'interventions are more effective if they take place during moments of change.' In other words, change can lead to sustained behaviour. Thus, during the COVID-19 lockdown, environmentally friendly behaviour might be travelling less, cutting down on food waste due to food shortages experienced in households, less environmental pollution, etc.

A study by Moser, Blumer and Hille (2018) buttressed this point when posited that, when people are unable to drive their cars due to certain problems, and they are given free e-bike access instead, they drove much less when they eventually get their car back. In a similar study by Fujii and Garling (2003), it was found out that when a motorway closed due to construction and other reasons forcing drivers to use public transit when the road eventually reopens, people who had formerly been committed drivers move less frequent personal cars, rather they rely on public transportation more frequently. We can assume that the restriction of car movement during the coronavirus is likely to change peoples' behaviour as some might drive less or take public transportation. Also, Jribi et al. (2020) study indicated that people whose social activities were limited during the coronavirus period were conscious of food waste, reduces waste, and displayed behaviours to prevent food waste.

\section{Conclusion}

While we try to leverage the environmental gain from the coronavirus, it should be noted that the fight to reclaim the earth from pillaging and plundering is far from being over. It just gives hope that the earth could be redeemed with positive environmental behaviour. Hence, the battle is up to every person living on the planet to decide whether to return to old habits or institute permanent changes in human routines. For instance, as the period of the coronavirus have illustrated, we do not need to drive to work or travel by 
air frequently as we can telecommute using platforms like Zoom or GoToWebinar app.

There is no doubt that the positive environmental outcome of COVID19 is only for a short moment, as was seen during the drops in emissions in the period of the global financial crash of 2008, which saw emissions rebounding in 2010. Thus, the situation might soon return to its initial state as countries and cities reopen. It is, therefore, wise for governments of various nations to support green energy through economic stimulus programs.

\section{References:}

1. Burke, M. (2020). COVID-19 reduces economic activity, which reduces pollution, which saves lives. Global Food, Environment and Economic Dynamics. Retrieved from: http://www.g-feed.com/2020/03/covid-19-reduces-economicactivity.html

2. CNN (April 2020). Jellyfish were seen swimming in Venice's canals. Retrieved from:

https://edition.cnn.com/travel/article/jellyfish-venice/index.html

3. Earth Observatory (2020). https://earthobservatory.nasa.gov/

4. Fujii, S., \& Gärling, T. (2003). Development of script-based travel mode choice after forced change. Transportation Research Part F: Traffic Psychology and Behaviour, 6(2), 117- 124.

DOI:10.1016/s1369-8478(03)00019-6

5. Ghansiyal, A. (2020). Before and After: The Environmental impact Of COVID-19 in cities. Retrieved from: https://travel.earth/environmental-impact-of-covid-19/

6. Green, M. (March 2020). Air pollution clears in northern Italy after coronavirus lockdown, satellite shows. Environment. Retrieved from; https://www.reuters.com/article/us- health- coronavirusitaly-pollution/air-pollution-clears-in-northern-italy-aftercoronavirus- lockdown-satellite-shows-idUSKBN2102X4

7. Henriques, M. (2020). Will Covid-19 have a lasting impact on the environment? Retrieved from:

https://www.bbc.com/future/article/20200326-covid-19-the-impact-

of- coronavirus-on-the-environment

8. Jribi, S., Ben Ismail, H., Doggui, D., \& Debbabi, H. (2020). COVID19 virus outbreak lockdown: What impacts on household food wastage? Environment, Development and Sustainability. https://doi.org/10.1007/s10668-020-00740-y

9. Kopnina, H., Washington, H., Taylor, B.J., \& Piccolo, J. (2018). Anthropocentrism: More than Just a Misunderstood Problem. 
Journal of Agricultural and Environmental Ethics. 31 (1): 109-127. DOI:10.1007/s10806-018-9711-1.

10. Madhav, N., Oppenheim, B., Gallivan, M., Mulembakani, P., Rubin, E., \& Wolfe, N. (2017), "Pandemics: Risks, Impacts, and Mitigation", In: Jamison, D.T.; Gelband, H. Horton, S. \& Jha, P. (eds.), Disease Control Priorities: Improving Health and Reducing Poverty (3rd ed.), The International Bank for Reconstruction and Development / The World Bank, doi:10.1596/978-1-4648$0527-1 / p t 5 . \operatorname{ch} 17$

11. McMahon, J. (2020). Study: Coronavirus lockdown likely saved 77,000 lives in China just by reducing pollution. Forbes. Retrieved from:

https://www.forbes.com/sites/jeffmcmahon/2020/03/16/coronaviruslockdown-may- have-saved-77000-lives-in-china-just-frompollution-reduction/\#7cc470a134fe

12. Moser, C., Blumer, Y., \& Hille, S.L. (2018). E-bike trials' potential to promote sustained changes in car owners mobility habits.

Environmental ResearchLetters.13. doi.org/10.1088/17489326/aaad73

13. Myllyvirta, L. (2020). Analysis: Coronavirus has temporarily reduced China's $\mathrm{CO} 2$ emissions by a quarter. Carbon Brief. Retrieved from: https://www.carbonbrief.org/analysis- coronavirus-hastemporarily-reduced-chinas-co2-emissions-by-a-quarter

14. Rull, V. (2016). The humanized earth system (HES). The Holocene. 26 (9): 1513-1516. DOI:10.1177/0959683616640053.

15. Saadat, S., Rawtani, D., \& Hussain, C.M. (2020). Environmental Perspective of COVID-19. Science of the Total Environment, 728, 1-6.

16. Shutterstock (June, 2020). A Brief Look at the Environmental Impacts of COVID-19. Retrieved from:

https://www.shutterstock.com/blog/environmental-impacts-of-covid19

17. Srikanth, A. (March 2020). As Italy quarantines over coronavirus, swans appear in Venice canals, dolphins swim up playfully. The Hill. Retrieved from: https://thehill.com/changingamerica/sustainability/environment/488286-italys- coronaviruslockdown-shows-what-nature

18. University of Cape Town-UTC (April 2020). South Africa: Lockdown brings unintended 'positive' environmental impact. Retrieved from: https://allafrica.com/stories/202004220456.html

19. Venter, Z.S., Aunan, K., Chowdhury, S., \& Lelieveld, J. (2020). "COVID-19 lockdowns cause global air pollution declines". 
Proceedings of the National Academy of Sciences. 117

18984-18990.DOI:10.1073/pnas.2006853117.

20. Zambrano-Monserrate, M.A., Ruano, M.A., \& Sanchez-Alcalde, L. (2020). Indirect effect of COVID-19 on the environment. Science of the Total Environment, 728, 1-4. doi.org/10.1016/j.scitotenv.2020.138813

21. Zhang, R., Zhang, Y., Lin, H., Feng, X., Fu, T-M., \& Wang, Y. (2020). NOx Emission Reduction and Recovery during COVID-19 in East China. Atmosphere. 11 (4): 433.

DOI: 10.3390/atmos11040433. 